\title{
Признаки магматического смешения в тефре вулкана Хангар (Срединный хребет, Камчатка) по данным геотермометрии
}

\author{
Толстых М.Л. ${ }^{1}$, Певзнер М.М. ${ }^{2}$ \\ ${ }^{1}$ Институт геохимии и аналитической химии им. В.И. Вернадского PAH, Mосква, mashtol@mail.ru \\ ${ }^{2}$ Геологический институт РАН, Москва
}

Аннотация. В тефре крупного кальдерообразующего извержения вулкана Хангар (возраст 7.9 тыс. л.н.) выявлены несколько минеральных парагенезисов, причем более высокотемпературный формировался позже, чем низкотемпературный. Повторное повышение температуры в системе могло быть вызвано инъекцией высокотемпературной глубинной магмы в кислый частичной раскристаллизованный очаг.

Ключевык слова: Островодужный вулканизм, тефра, риолиты, дациты, Камчатка, Срединный хребет.

\section{Magma mixing in the tephra of the Khangar volcano: evidence of geothermometry}

\author{
Tolstykh M.L. ${ }^{1}$, Pevzner M.M. ${ }^{2}$ \\ ${ }^{I}$ Vernadsky Institute of Geochemistry and Analytical Chemistry of Russian Academy of Sciences (GEOKHI RAS) \\ ${ }^{2}$ RAS Geological Institute (GIN RAS)
}

\begin{abstract}
The mineral parageneses in the tephra of a large caldera-forming eruption of the Hangar volcano (age 7900 years ago) demonstrate a difference of a forming temperature. The higher-temperature parageneses were formed later than the low-temperature one. The increase in temperature in magmatic system could be caused by the injection of high-temperature magma into the magmatic chamber of silicic compositiion.
\end{abstract}

Keywords: Island-arc volcanism, tephra, rhyolites, dacites, Kamchatka, Sredinny range.

Хангар (54²5’ с.ш., 157²4’ в.д., высота 2000 м) - самый южный вулкан Срединного хребта расположен в крупной тектонической кальдере, заложенной на гранито-гнейсовом куполе в процессе формирования активного вулканического пояса Срединного хребта Камчатки. История вулканической активности центра Хангар составляет около 7 млн. лет (Певзнер, 2019), причем за это время неоднократно менялись тип извержений и состав продуктов. Около 7.9 тыс. л. н. (Cook et al., 2018) произошло мощное извержение стратовулкана Хангар (индекс ХГ), в ходе которого было образо-

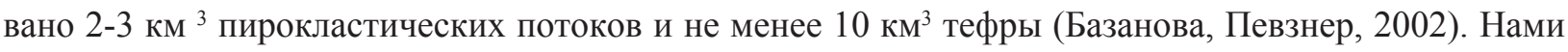
были изучены образцы тефры ХГ.

Крупные (до 7 см) лапилли риодацитового состава сложены вспененным стеклом (пористость не более 30-40 \%), а также вкрапленниками плагиоклаза, кварца, биотита, амфиболов в объемных соотношениях $50: 25: 20: 5$, соответственно. Вкрапленники составляют около 30 об.\% породы. Акцессорные минералы представлены титаномагнетитом, апатитом, цирконом и монацитом. Циркон и монацит были обнаружены исключительно в виде кристаллических включений в крупных вкрапленниках биотита и реже кварца.

Минералы вкрапленников риодацитовой тефры ХГ фиксируют нарушение равновесных условий при кристаллизации.

Плагиоклазы. Можно выделить плагиоклазы двух генераций: An 55-69 и An 22-42 соответственно. Наиболее основные плагиоклазы $(A n>50)$ встречаются редко (не более 5 \% проанализированных плагиоклазов), лишь в виде реликтовых резорбированных зон в крупных зернах (рис. 1б) или в виде включений в биотите. Плагиоклаз этой генерации характеризуется повышенным содержанием $\mathrm{FeO}$ (до 0.7 мас. \%) и пониженным - $\mathrm{K}_{2} \mathrm{O}$ (около 0.1 мас. \%). Вкрапленники плагиоклазов олигоклаз-андезинового ряда характеризуются сложной повторяющейся зональностью, часто обратной, с незначительным диапазоном анортитовой составляющей An 22-32 (рис. 1a), иногда до $A n 42$ в кайме. Более кислый плагиоклаз (An 24-30) также широко распространен в виде кристалли- 

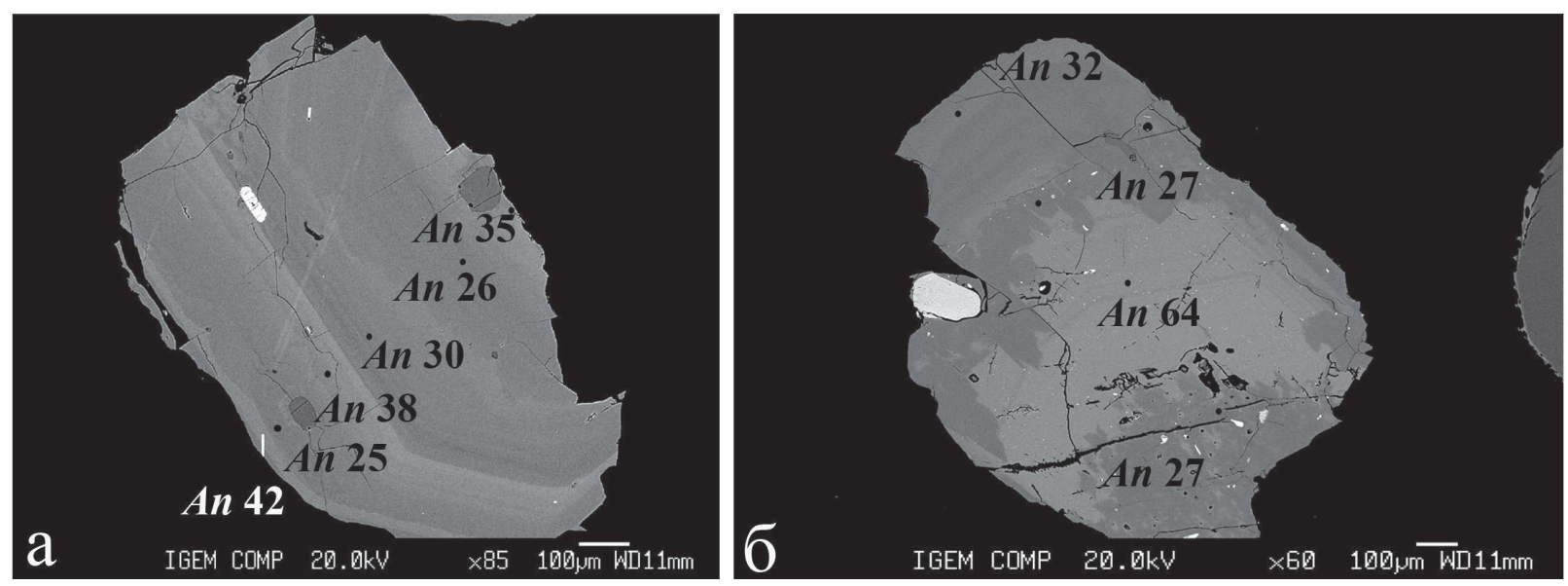

Рис. 1. Зональные вкрапленники плагиоклаза тефры извержения ХГ. Изображения получены при помощи микроанализатора Jeol JXA 8200, ИГЕМ РАН.

Fig. 1. P1 phenocrysts of tephra from the KHG eruption. Image by Jeol JXA 8200, IGEM RAS.

ческих включений в кварце, более основном плагиоклазе и биотите, а также в составе полиминеральных агрегатов реакционных кайм по биотиту (рис. 2 а) и микролитов.

Эти плагиоклазы характеризуются относительно высокими концентрациями $\mathrm{K}_{2} \mathrm{O}$ - до 0.6 мас. \% и кремнезема - 58-62 мас. \% (табл. 1). Таким образом, плагиоклазы регистрируют сложную многостадийную историю магмогенеза с кратковременной дестабилизацией условий в очаге, зафиксированной в зоне роста основного плагиоклаза (рис. 1 б), заключенной внутри плагиоклазов между более кислым ядром и внешней каймой.

К сожалению, возможность использования геотермометров, основанных на равновесии «плагиоклаз-расплав» (Putyrka et al., 2008, Kudo, Weill, 1970) ограничивается из-за проблем с измерением содержания натрия в стеклах кислых водосодержащих включений (Spray, 1995), а также отсутствием расплавных включений в зонах наиболее кальциевого плагиоклаза. Однако для нескольких пар «кислый плагиоклаз-стекловатое включение» (Толстых, 2018) были получены температуры 744-783 $\square$.

Таблица 1. Представительные анализы минеральных фаз и расплавных включений тефры ХГ.

Table 1. Representative analyses of mineral phases and melt inclusions of tephra KHG.

\begin{tabular}{|c|c|c|c|c|c|c|c|c|}
\hline Компонент & 1 & 3 & 3 & 4 & 5 & 6 & 7 & 8 \\
\hline $\mathrm{SiO}_{2}$ & 50.08 & 58.37 & 61.72 & 71.68 & 47.96 & 44.89 & 38.12 & 38.89 \\
\hline $\mathrm{TiO}_{2}$ & - & - & & 0.12 & 1.18 & 2.04 & 4.09 & 4.25 \\
\hline $\mathrm{Al}_{2} \mathrm{O}_{3}$ & 31.59 & 25.36 & 23.32 & 11.28 & 7.01 & 9.70 & 14.23 & 14.48 \\
\hline $\mathrm{FeO}$ & 0.73 & 0.22 & 0.15 & 0.48 & 11.16 & 12.37 & 15.28 & 12.19 \\
\hline $\mathrm{MnO}$ & - & - & - & 0.06 & 0.69 & 0.56 & 0.35 & 0.18 \\
\hline $\mathrm{MgO}$ & - & - & - & 0.13 & 16.21 & 14.17 & 15.18 & 16.16 \\
\hline $\mathrm{CaO}$ & 14.33 & 7.01 & 4.51 & 0.50 & 11.01 & 10.47 & 0.26 & 0.16 \\
\hline $\mathrm{Na} 2 \mathrm{O}$ & 3.56 & 7.41 & 8.61 & 3.9 & 1.41 & 1.92 & 0.50 & 0.84 \\
\hline $\mathrm{K}_{2} \mathrm{O}$ & 0.10 & 0.45 & 0.64 & 3.96 & 0.29 & 0.45 & 7.35 & 7.50 \\
\hline $\mathrm{Cl}$ & - & - & - & 0.09 & 0.01 & 0.02 & 0.30 & 0.46 \\
\hline $\mathrm{F}$ & - & - & - & - & - & 0.44 & 0.09 & 0.08 \\
\hline Сумма & 100.39 & 99.82 & 98.15 & 92.24 & 96.93 & 97.03 & 95.75 & 95.19 \\
\hline
\end{tabular}

Примечание: 1-3 - вкрапленники плагиоклаза An 69, 33,27; 4 - расплавное включение в плагиоклазе; 5 - среднеразмерный вкрапленник амфибола; 6 - зерно амфибола из каймы обрастания по биотиту; 7, 8 - вкрапленники биотита.

Биотит является наиболее распространенным темноцветным минералом в породах, представлен в виде разноразмерных идиоморфных вкрапленников, а также в виде зерен в полиминераль- 

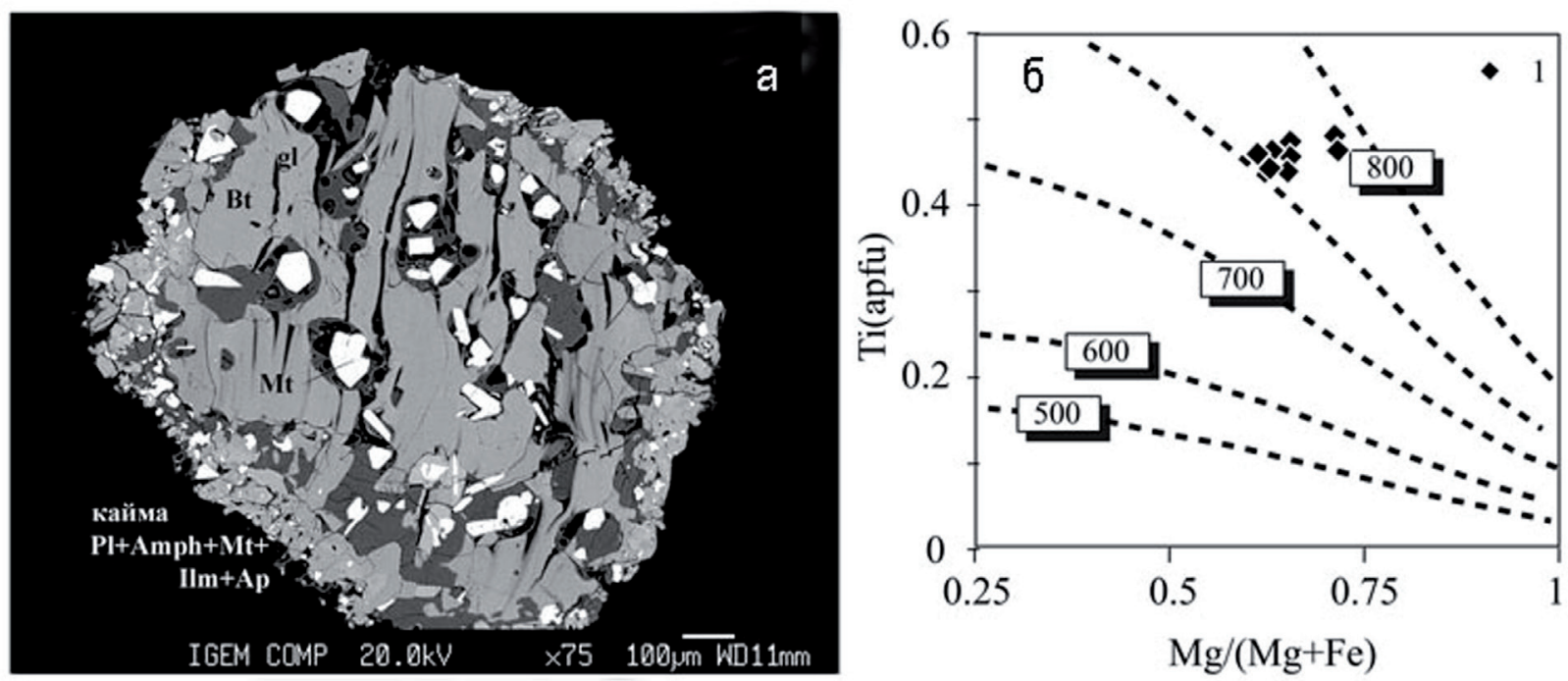

Рис. 2. а - вкрапленник биотита тефры ХГ (изображение получено при помощи микроанализатора Jeol JXА 8200, ИГЕМ РАН); б - вариационная диаграмма \#Мg-Ті для биотита согласно мономинеральному термометру (Henry et al., 2005). 1 - биотиты ХГ.

Fig. 2. a - biotite phenocryst (image by the Jeol JXA 8200 IGEM RAS); b - variation diagram \# Mg-Ti for biotite according to the monomineral thermometer (Henry et al., 2005). 1 - biotite KHG.

ных агрегатах. Все вкрапленники биотита схожи по составу (табл. 1) и насыщены кристаллическими включениями рудного минерала (титаномагнетита), плагиоклаза, апатита, цирконов и монацита. Некоторые вкрапленники сильно разрушены и окружены поликристаллической каймой (рис. 2 a), которую составляют плагиоклаз, амфибол и акцессорные минералы: апатит, ильменит, титаномагнетит.

Температуры кристаллизации биотита, рассчитанные согласно мономинеральному термометру (Henry et al., 2005), также укладываются в диапазон 755-785 $\square$ (рис. 2 б), хотя данный термометр разработан для метаморфических систем, и для реконструкции магматических процессов его следует применять с осторожностью.

Амфибол чрезвычайно редко встречается в виде отдельных вкрапленников. Как правило, такие зерна отличаются сильным удлинением, окружены более мелкими зернами амфибола того же состава и содержат огромное количество кристаллических включений. Амфибол отдельных вкрапленников отвечает по составу роговым обманкам, в то время как выделения амфибола в полиминеральных каймах по биотиту относятся к чермакит-паргаситовому ряду, обогащены глиноземом и титаном (табл. 1).

Согласно амфиболовому геотермобарометру (Ridolfi et al, 2010), амфиболы вкрапленников кристаллизовались при давлениях не более 2 кбар при температурах 760-787 $\square$, а более титанистые амфиболы кайм по зернам биотита - при температурах 834-874 $\square$ (рис. 3 б). Рассчитанные по этой же программе содержания $\mathrm{H}_{2} \mathrm{O}$ в расплаве составляют в среднем 4.65 и 5.65 мас. \%, соответственно, что сопоставимо с данными SIMS по стеклам расплавных включений.

Акцессорные минералы. К наиболее распространенным акцессориям относятся рудные минералы (титаномагнетит, ильменит), а также фтор-апатит. Кроме того, в виде кристаллических включений в кварце и биотите обнаружены циркон и монацит, причем по составу эти кристаллические включения в разных минералах практически идентичны (табл. 4, 5). Кроме того, нами были отобраны и проанализированы зерна цирконов из гранитоидов массива, лежащего в основании вулканической структуры Хангар, поскольку не исключена возможность ассимиляции магмами материала гранитов.

Согласно мономинеральному геотермометру (Watson et al., 2006) значения, рассчитанные для цирконов тефры ХГ и гранитоидов образуют два перекрывающихся поля (рис. 4б), 730-802 $\square$ и 840-912 $\square$ причем среди цирконов тефры ХГ больше высокотемпературных разностей, чем сре- 

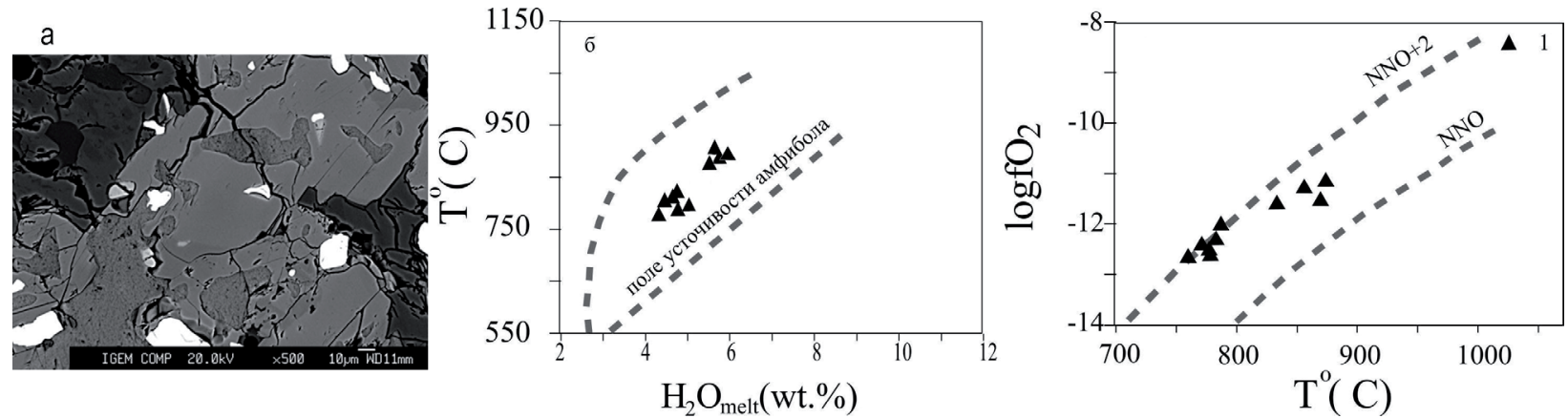

Рис. 3. а - вкрапленник амфибола со включениями биотита; 6 - вариационные диаграммы Т $\square-\log \mathrm{fO}_{2}$ и $\mathrm{H}_{2} \mathrm{O}$ мас. \% - Т для амфиболов по данным мономинерального геотермометра (Ridolfi et al., 2010). 1 - амфиболы ХГ.

Fig. 3. a - amphibole phenocrysts with biotite inclusions; $b$ - variation diagrams $\mathrm{T} \square-\log \mathrm{fO}_{2}$ and $\mathrm{H}_{2} \mathrm{O}$ wt. $\%-\mathrm{T}$ for amphiboles according to monomineral geothermometer data (Ridolfi et al., 2010). 1 - amphiboles KHG.

ди цирконов гранитоидов. Однако, не исключено, что цирконы тефры могут быть расценены как ксенокристы гранитоидов в связи со сходством их морфологии и микроэлементного состава (Толстых и др., 2020).

Таким образом, среди минералов тефры ХГ выделено как минимум два парагенезиса, кристаллизовавшихся при разных температурах: высокотемпературный, представленный амфиболом реакционных кайм, цирконом и, возможно, основным плагиоклазом, соответствует диапазону около 840-900 $\square$, и низкотемпературный (кислый плагиоклаз, биотит, амфибол), соответствующий диапазону 730-780 $\square$. Поскольку более высокотемпературные фазы (зоны более основного плагиоклаза вокруг ядер более кислого состава или реакционные каймы вокруг зерен биотита) часто образовывались после формирования низкотемпературного парагенезиса, можно предполагать, что повторное повышение температуры в магматической камере или какой-то ее области является признаком магматического смешения - внедрением более высокотемпературного расплава в кислый очаг.
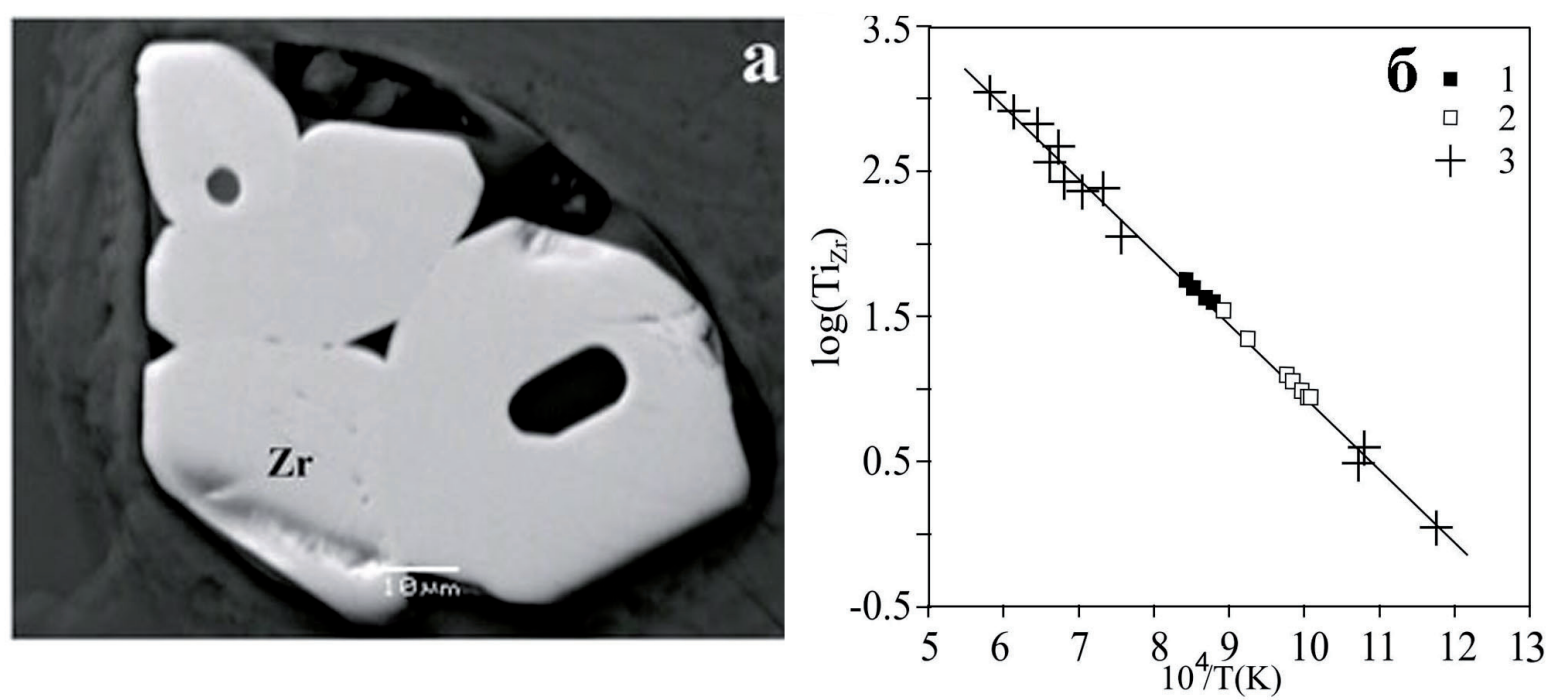

Рис. 4. а - кристаллическое включение циркона в биотите тефры ХГ; б - вариационная диаграмма $\mathrm{T} \square-\mathrm{Ti}_{\mathrm{Zr}}$ для цирконов согласно мономинеральному термометру (Watson et al, 2006). Активность титана в системе определена согласно методу (Wark, Watson, 2004). 1 - циркон ХГ, 2 - циркон гранитоидов, 3 - экспериментальные данные из работы (Watson et al., 2006).

Fig. 4. a - the crystal inclusion of zircon in the biotite of tephra KHG; $b$ - the $\mathrm{T} \square-\mathrm{Ti} \mathrm{Zr}_{\mathrm{zr}}$ variation diagram for zircons according to the monomineral thermometer (Watson et al, 2006). The activity of Ti in the system is determined according to the method (Wark, Watson, 2004). 1 - zircons KHG, 2 - zircons from granite, 3 - experimental data from (Watson et al, 2006). 
Работа выполнена в рамках темы государственного задания № 0137-2019-0014 и частичной финансовой поддержке гранта РФФИ 20-05-00085.

\section{Литература}

1. Базанова Л.И., Певзнер М.М. (2001) Хангар - еще один действующий вулкан на Камчатке // ДАН. 2001.T. 377. № 6. С. 800-802.

2. Певзнер М.М., Лебедев В.А., Волынец А.О., Толстых М.Л., Костицын Ю.А., Бабанский А.Д. Возраст стратовулканов Ичинский и Хангар (Срединный хребет, Камчатка) // ДАН. 2019. Т. 489. № 6. Р. $82-86$.

3. Толстых М.Л., Наумов В.Б., Певзнер М.М., Бабанский А.Д. Расплавы, формировавшие тефру извержения 6900 вулкана Хангар (Срединный хребет, Камчатка) // Материалы ТБГ. 2018. С. 126-128.

4. Толстых М.Л., Бабанский А.Д. Акцессорные минералы как маркер участия гранитоидов фундамента в формировании магм вулканического центра Хангар (Срединный хребет, Камчатка) // Труды Ферсмановской научной сессии ГИ КНЦ РАН. 2020. Т. 17. С. 530-533. https://doi.org/10.31241/FNS.2020.17.102.

5. Cook E., Portnyagin M., Ponomareva V., Bazanova L., Svensson A., Garbe-Schönberg D. (2018) First identification of cryptotephra from the Kamchatka Peninsula in a Greenland ice core: implications of a widespread marker deposit that links Greenland to the Pacific northwest // Quaternary Science Reviews. 2018. V. 181. P. 200-206. doi:https://doi.org/10.1016/j.quascirev.2017.11.036.

6. Henry D.J., Guidotti C.V., Thomson J.A. The Ti-saturation surface for low-to-medium pressure metapelitic biotites: Implications for geothermometry and Ti-substitution mechanisms // Am. Mineralogist. 2005. V. 90. P. 316-328.

7. Kudo A.M., Weill D.F. An igneous plagioclase thermometer//Contrib Mineral Petrol. 1970. V. 25. P. 52-65.

8. Putirka K. Igneous thermometers and barometers based on plagioclase + liquid equilibria: tests of some existing models and new calibrations // American Mineralogists. 2005. V. 90. P. 336-346.

9. Ridolfi F., Renzulli A., Puerini M. Stability and chemical equilibrium of amphibole incalc-alkaline magmas: an overview, new thermobarometric formulations and applicationto subduction-related volcanoes // Contributions to Mineralogy and Petrology. 2010. V. 160. P. 45-66.

10. Spray J.G. Quantitative electrone-microprobe analysis of alkali silicate glasses: a rewiew and user guide// Canad. Mineral. 1995. V. 33. P. 323-332.

11. Wark D.A., Watson E.B. Launching the TITANiQ: titanium-in-quartz thermometer. Geochim. Cosmochim. Acta. 68, A 543.

12. Watson E. B., Wark D. A., Thomas J. B. Crystallization thermometers for zircon and rutile// Contrib. Mineral. Petrol. 2006. V. 151. P. 413-433. 